\title{
A Coletividade como Possibilidade de Resistência ao Trabalho Abstrato na Docência
}

\section{The Collective as a Possibility of Resistance to Abstract Work in Teaching}

\section{La Colectividad como Posibilidad de Resistencia al Trabajo abstracto en la Docencia}

\author{
Andrade, Susimeire Vivien Rosotti ${ }^{1}$ (Foz do Iguaçu, Paraná, Brasil) \\ https://orcid.org/0000-0001-9188-8620 \\ Sândalo, Patrícia Pereira² (Campo Grande, Mato Grosso do Sul, Brasil) \\ https://orcid.org/0000-0002-7554-0058
}

\begin{abstract}
Resumo
O artigo é fundamentado na Perspectiva Histórico-Cultural em consonância com o Materialismo Histórico-Dialético, apresenta uma investigação teórico-bibliográfica desenvolvida no âmbito do doutorado finalizado em 2020, discute sobre a compreensão da coletividade para afirmar a relevância da resistência ao trabalho abstrato na docência. Ao articular as categorias possibilidade-realidade a pesquisa demonstra que a coletividade torna essencial uma auto-organização na qual o trabalho entre os membros seja uma atividade fonte de formação dos mesmos e desenvolvimento, que corroboram para a transformação da sociedade. Sabe-se que essa orientação não serve aos interesses do modo de produção capitalista cujo trabalho abstrato atende aos interesses econômicos. O professor não foi poupado destes interesses e o seu trabalho, cujo significado o torna responsável pela educabilidade do ser humano, é fonte de sua formação e desenvolvimento, mas indissociável do indivíduo-sociedade. A realidade evidencia que os professores vivenciam os resultados das mudanças políticas ocorridas no Brasil, em 2016, que favoreceu a agenda neoliberal da educação, que visa atender ao sistema capitalista, portanto, um retrocesso para o trabalho docente. Como realidade-possibilidade são indissociáveis, a coletividade torna-se imprescindível aos professores, pois através dela é favorecido aos membros a compreensão da realidade que é imprescindível no estabelecimento de caminhos para a luta, pois os que vivem nela sabem que há momentos de avançar e momentos de resistir, sendo que este não é sinônimo de imobilismo e, sim, um caminho para avançar.
\end{abstract}

Palavras-chave: Trabalho. Docência. Modo de produção. Coletividade.

\begin{abstract}
The article is based on the Historical-Cultural Perspective in line with Materialism Dialectical, presents a theoretical-bibliographic investigation developed in the scope of the doctorate finalized in 2020, discusses the comprehension of the collective to affirm the relevance of resistance to abstract work in teaching. By articulating the possibility-reality categories, the research shows that the collectivity makes essential a self-organization in which the work among the members is a source of their formation and development, which corroborate for the transformation of society. It is known that such guidance does not serve the interests of the production method capitalist whose abstract labor serves economic interests. The teacher was not spared these interests and his work, whose meaning makes him responsible for the human being's education, is the source of his formation and development, but inseparable from the individual-societyThe reality shows that teachers experience the results of the political changes that occurred in Brazil in 2016, which favored the neoliberal agenda of education, which aims to meet the capitalist system, therefore, a setback to teaching work. As reality-possibility are inseparable, the collective becomes indispensable to teachers, because through it is favored members the understanding of reality that is indispensable in establishing paths to the struggle, For those who live in it know that there are moments to advance and moments to resist, and this is not synonymous with immobilism, but a way forward.
\end{abstract}

Keywords: Work. Teaching. Mode of production. Collectivity

\footnotetext{
1 Centro de Engenharias e Ciências Exatas. Programa de Pós-Graduação em Ensino (PPGEn) da Universidade Estadual do Oeste do Paraná (UNIOESTE). susimeire.andrade@unioeste.br

2 Departamento de Matemática. Programa de Pós-Graduação em Educação Matemática e Docente do Doutorado em Ensino de Ciências da Universidade Federal de Mato Grosso do Sul (UFMS). sandalo.patricia13@gmail.com 


\section{Resumen}

El artículo se basa en la Perspectiva Histórico-Cultural en consonancia con el Materialismo Dialéctico, presenta una investigación teórico-bibliográfica desarrollada en el ámbito del doctorado finalizado en 2020, discute sobre la comprensión de la colectividad para afirmar la relevancia de la resistencia al trabajo abstracto en la docência. Al articular las categorías posibilidad-realidad la investigación demuestra que la colectividad hace esencial una auto-organización en la que el trabajo entre los miembros sea una actividad fuente de formación de los mismos y desarrollo, que corroboran para la transformación de la sociedad. Se sabe que esta orientación no sirve a los intereses del modo de producción capitalista cuyo trabajo abstracto atiende a los intereses económicos. El profesor no se ha librado de estos intereses y su trabajo, cuyo significado lo hace responsable de la educabilidad del ser humano, es fuente de su formación y desarrollo, pero indisociable del individuo-sociedad. La realidad evidencia que los profesores experimentan los resultados de los cambios políticos ocurridos en Brasil, en 2016, que favoreció la agenda neoliberal de la educación, que busca atender al sistema capitalista, por lo tanto, un retroceso para el trabajo docente. Como realidad-posibilidad son indisociables, la colectividad se hace imprescindible a los profesores, pues a través de ella se favorece a los miembros la comprensión de la realidad que es imprescindible en el establecimiento de caminos para la lucha, pues los que viven en ella saben que hay momentos de avanzar y momentos de resistir, siendo que éste no es sinónimo de inmovilismo y, sí, un camino para avanzar.

Palavras-Clave: Trabajo. Docencia. Modo de producción. Colectividad

\section{Introdução}

Com fundamentação na Perspectiva Histórico-Cultural em consonância com o Materialismo Histórico-Dialético, o presente estudo tem por objeto a interrelação entre a coletividade de professores e a resistência ao trabalho abstrato. Assim, apresenta uma investigação teórico-bibliográfica desenvolvida no âmbito do doutorado finalizado no ano de 2020, cujo objetivo é analisar e discutir o conceito de coletividade para afirmar a relevância da resistência ao trabalho abstrato na docência.

A Perspectiva Histórico-Cultural se origina nos estudos desenvolvidos por vários grupos de pesquisadores na década de 1920, na antiga União Soviética. O processo revolucionário contribuiu para a união de vários pesquisadores, de diferentes áreas do conhecimento, que objetivavam a construção de uma nova sociedade, portanto, de um novo homem. Os grupos de pesquisa optaram pelo método de investigação intitulado Materialismo Histórico-Dialético (MHD) elaborado por Karl Marx (1818-1883) e Friedrich Engels (1820-1895).

No MHD, o investigador discute os conceitos e as categorias que permitem ao pesquisador a interpretação e a análise do material, pois é "na análise que se estabelecem as relações entre a parte e a totalidade" e a síntese da investigação "é a exposição, orgânica, coerente, concisa das múltiplas determinações que explicam a problemática investigativa", assim, ela avança no conhecimento do objeto estudado e, além disso, "nas questões pendentes e a própria redefinição das categorias, conceitos" (FRIGOTTO, 2010, p. 98).

Com base na orientação teórico-metodológica, o objeto existe 
Programa de Pós-graduação em Educação, Universidade Federal do Ceará

Fortaleza-CE-Brasil

independente do pesquisador, assim, para ir além das aparências fenomênicas, a essência da sua análise articula as categorias do MHD possibilidade-realidade, concebe que estas são indissociáveis, pois "a realidade é o que existe realmente e a possibilidade é o que pode produzir-se quando as condições são propícias" (CHEPTULIN, 1982, p. 338). Considerando que a realidade, no modo de produção da vida material, é o cerne para se entender a organização de uma sociedade e o trabalho é um processo que constitui o ser humano como ser genérico, sendo fonte de formação e desenvolvimento humano, que o distinguiu dos outros animais, por natureza visa uma coletividade.

Considerando orientação teórico-metodológica deste estudo que tem como objeto a inter-relação entre a coletividade de professores e a resistência ao trabalho abstrato, articula as categorias possibilidade-realidade indica uma "postura materialista histórica na construção do conhecimento" concebe que, no processo, para ser "dialética, a teoria, que fornece as categorias de análise, necessita, no processo de investigação, ser revisada, e as categorias reconstituídas" (FRIGOTTO, 2010, p. 89-95).

Assim, em uma sociedade que é dividida em classes como a capitalista, onde a sua organização social do trabalho visa atender aos seus interesses econômicos, o trabalho será abstrato, que acentua a exploração e opressão dos trabalhadores. Os professores não foram poupados deste modo de produção social do trabalho e o trabalho que teria como significado ser a fonte de formação e desenvolvimento dos seus alunos, que de forma direta os torna responsáveis pelo processo de humanização dos seres humanos, resume-se a garantir a própria sobrevivência.

Na escola, como nas demais instituições sociais, a auto-organização dos seres humanos deve corroborar com a manutenção do sistema capitalista, para tanto, parte do trabalho abstrato, cuja competição e individualidade são essenciais, e que não corrobora para a coletividade de professores, e sim, apenas em uma mera associação entre eles. Desta forma, defende que a coletividade de professores cuja auto-organização parte do trabalho como fonte de formação e desenvolvimento humano favorece uma solidariedade entre os membros e o compromisso com a seu trabalho como uma possibilidade de resistência ao trabalho abstrato na docência.

O estudo organizou-se da seguinte forma: primeiro analisa e discute o 
Programa de Pós-graduação em Educação, Universidade Federal do Ceará

Fortaleza-CE-Brasil

conceito do trabalho como atividade, diferenciando do trabalho abstrato para apreender o conceito de coletividade segundo a orientação teórico-metodológica deste estudo e, em seguida, articulam os conceitos estudados para afirmar a relevância da resistência ao trabalho abstrato na docência, e finaliza com algumas considerações do que foi exposto.

\section{Discutindo o conceito de trabalho como atividade orientada a um fim e o Trabalho abstrato}

Lombardi (2011), estudioso de Marx, ressalta o que "homem é, é pelo trabalho" sendo que a sua essência "é um feito humano" visto que, não nasce homem torna-se, em outras palavras "ele forma-se homem" (LOMBARDI, 2011, p. 103) e ao nascer, precisa efetivar o processo de apropriação das objetivações produzidas pela humanidade para garantir a sua formação e desenvolvimento.

As pesquisas de Leontiev (1978), membro do grupo de L. S. Vigotski que compõem o cerne da Perspectiva Histórico-Cultural, conseguiram articular o social, o histórico e o cultural para investigar as Funções Psicológicas Superiores (FPS) que são tipicamente humanas. Assim, acrescenta "o aparecimento e o desenvolvimento do trabalho, condição primeira e fundamental da existência do homem, acarretaram a transformação e a hominização do cérebro, dos órgãos de atividade externa e dos órgãos dos sentidos" (LEONTIEV, 1978, p. 68).

O trabalho é concebido como uma atividade, e o ser humano, ao diferenciar-se dos outros animais a partir do trabalho, desencadeou as necessidades específicas humanas, tornando-o, assim, um ser histórico que tem necessidades socioculturais e mobilizam a geração de novas apropriações e objetivações. 0 "processo de apropriação realiza a necessidade principal e o princípio fundamental do desenvolvimento ontogênico humano - a reprodução nas aptidões e propriedades do indivíduo", isto é, "das aptidões e propriedades historicamente formadas da espécie humana, inclusive a aptidão para compreender e utilizar a linguagem" (LEONTIEV, 1978, p. 172).

Ademais, considera que o ser humano, ao longo de sua existência, é marcado por três Atividades-Guias: brincadeira na infância, a Atividade de Estudo que inicia com a entrada na escola e o trabalho na vida adulta. Estas Atividades têm um significado histórico, pois "o indivíduo é colocado diante de uma imensidade de 
Programa de Pós-graduação em Educação, Universidade Federal do Ceará Fortaleza-CE-Brasil

riquezas acumuladas ao longo dos séculos por inumeráveis gerações de homens, os únicos seres, no nosso planeta, que são criadores" (LEONTIEV, 1978, p. 67) e deve coincidir com o sentido pessoal para, de fato, constituir uma atividade humana.

As Atividades-Guias são as mais decisivas no processo do desenvolvimento humano, sendo que uma atividade humana é constituída de necessidades, motivos espontâneos e geradores de sentido, operações, ações, condições e objeto que se entrelaçam instituindo a consciência que tem como componentes o significado social, sentido pessoal e os conteúdos sensíveis que são representações, imagens de percepção, sensações. Os animais realizam ações em conjunto, mas não desenvolvem um trabalho coletivo, isto é, uma atividade. Desse modo, para os animais, a sua aprendizagem visa adaptação e seu desenvolvimento é marcado somente pelas condições biológicas, enquanto que para o ser humano a aprendizagem visa a apropriação das objetivações que possibilita o seu desenvolvimento ontológico, que é a unidade entre o individual e o social.

Neste sentido, a atividade preconiza um trabalho coletivo que tem no cerne a essência do ser humano, inter-relaciona com sua formação e desenvolvimento, que têm origem social e se concretizam na cooperação entre todos, gerando a necessidade da "divisão técnica, embrionária que seja, das funções de trabalho; assim, o trabalho é uma ação sobre a natureza, ligando entre si os participantes, mediatizando a sua comunicação" (LEONTIEV, 1978, p. 75). Nas comunidades primitivas, não existia a propriedade privada, somente a coletiva colocando todos "os homens em relações idênticas em relação aos meios e frutos da produção, sendo estes últimos, portanto, refletidos de maneira idêntica na consciência individual e na consciência coletiva" (LEONTIEV, 1978, p. 114).

No modo de produção onde há divisão de classes a sua organização social preconiza que o trabalho atenda à produção econômica, desta forma, não é sinônimo de trabalho como uma atividade orientada a um fim, isto é, um trabalho coletivo que, vislumbra a realização histórica do homem. Ao contrário, na sociedade onde há divisão de classes, o homem se transformando em fonte de exploração e opressão, e esse modo de produção visa o trabalho como categoria econômica como está esquematizado na Figura 1: 
Programa de Pós-graduação em Educação, Universidade Federal do Ceará Fortaleza-CE-Brasil

Figura1: Distinção de trabalho, em geral, e trabalho como categoria econômica
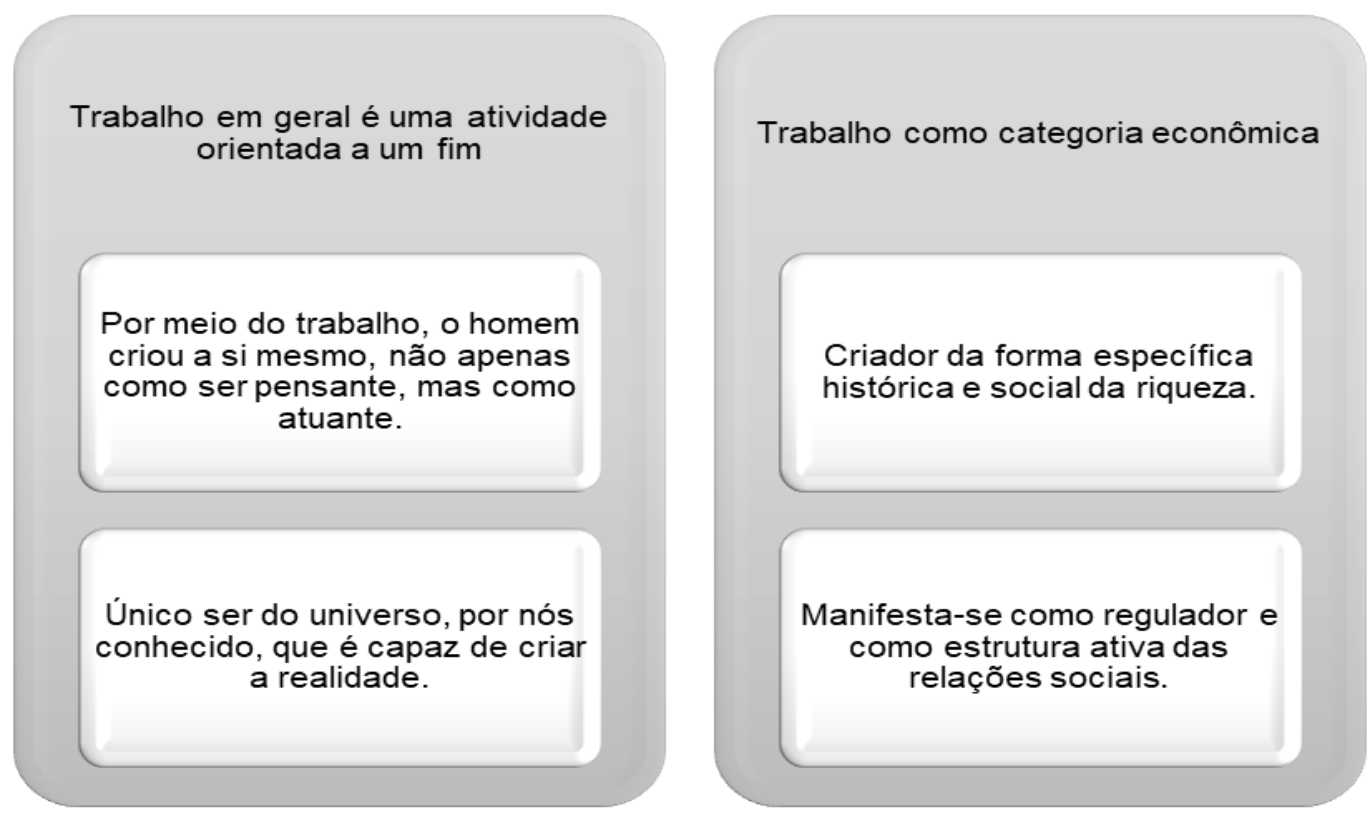

Fonte: Elaborada pelas autoras, a partir de Kosik (1976).

Na relação entre o trabalho humano e a criação da realidade humano-social "não descobrimos no trabalho nada de econômico", pois a "economia é a esfera da satisfação das exigências elementares do homem como ser fisiológico, biológico e animal" e "desempenha uma função decisiva apenas nas situações ínfimas, quando todos os interesses humanos se retiram e fica apenas a urgente necessidade de comer, agasalhar-se e vestir-se" (KOSIK, 1976, p. 190). Para tanto, o trabalho como categoria econômica é "um determinado trabalho, o trabalho abstrato-concreto ou um trabalho dotado de dupla natureza, e apenas nesta forma pertence à economia" (KOSIK, 1976, p. 191).

Segundo Marx (2017), o trabalho como categoria econômica não é sinônimo do trabalho, em geral, que preconiza uma "atividade orientada a um fim", fonte de formação e desenvolvimento humano, e como o modo de produção da vida material é o cerne para se entender a organização de uma sociedade considera que o rompimento da divisão artesanal do trabalho para o manufatureiro que "não só submete ao comando e à disciplina do capital o trabalhador antes independente como também cria uma estrutura hierárquica entre os próprios trabalhadores" que produz mercadoria (MARX, 2017, p. 298).

O autor destaca que as mercadorias são uma forma elementar de riqueza, pois elas vêm ao mundo "na forma de valores de uso ou corpos de mercadorias como: ferro, linho, trigo etc. Essa é sua forma natural originária", mas "só são mercadorias 
Programa de Pós-graduação em Educação, Universidade Federal do Ceará

Fortaleza-CE-Brasil

porque são algo duplo: objetos úteis e, ao mesmo tempo, suportes de valor. Por isso, elas só aparecem como mercadorias ou só possuem a forma de mercadorias na medida em que possuem esta dupla forma: a forma natural e a forma de valor" (MARX, 2017, p. 105).

$\mathrm{Na}$ teoria do valor, desenvolvida pelo autor, a mercadoria preconiza uma inter-relação do valor do uso e valor da troca, pois "a força de trabalho se torna mercadoria, o mais-trabalho extorquido" assume a forma de mais-valia, a "força de trabalho ou capacidade de trabalho entendemos o complexo [Inbegriff] das capacidades físicas e mentais que existem na corporeidade [Leiblichkeit], na personalidade viva de um homem e que ele põe em movimento sempre que produz valores de uso de qualquer tipo" (MARX, 2017, p. 242). O Capital é a força econômica desta sociedade que tudo domina, consequentemente, os seus detentores compram a força de trabalho visando produção de uma dada mercadoria. Tornou-se imprescindível que os meios de produção pertencessem a uma pessoa ou a um grupo que tivesse capital, que pode assumir diversas formas.

No sistema capitalista há exploração da força de trabalho, isto é, da maisvalia, na qual os trabalhadores não recebem. $O$ trabalho abstrato ao visar atender o sistema visa a sua manutenção que tem o cerne na exploração do trabalho vivo, que concebido com "a força criadora de valor", pois "o capital é trabalho morto que, como um vampiro, se reanima sugando o trabalho vivo, e, quanto mais o suga, mais forte se torna". O trabalho abstrato visa a categoria econômica, portanto, não preconiza trabalho coletivo como uma atividade orientada a um fim, pois quando há o trabalho em conjunto visa permitir distribuir as diferentes operações entre diferentes braços e, desse modo, executá-las simultaneamente, encurtando o tempo de trabalho necessário para a fabricação do produto total, "método empregado pelo capital para explorá-lo de maneira mais lucrativa, por meio do aumento de sua força produtiva" (MARX, 2017, p. 509).

No sistema capitalista, a auto-organização dos seres humanos parte do trabalho abstrato que vislumbra "associação que é a configuração específica de horda determinada por um objetivo comum imediato" o seu princípio ativo é a competição" (MOURA et.al, 2016, p. 252), que contribui para a organização social do trabalho, portanto, com a manutenção do sistema, como esquematizado na Figura 2. 
Figura 2- A diferença entre o princípio ativo, competição e fraternidade

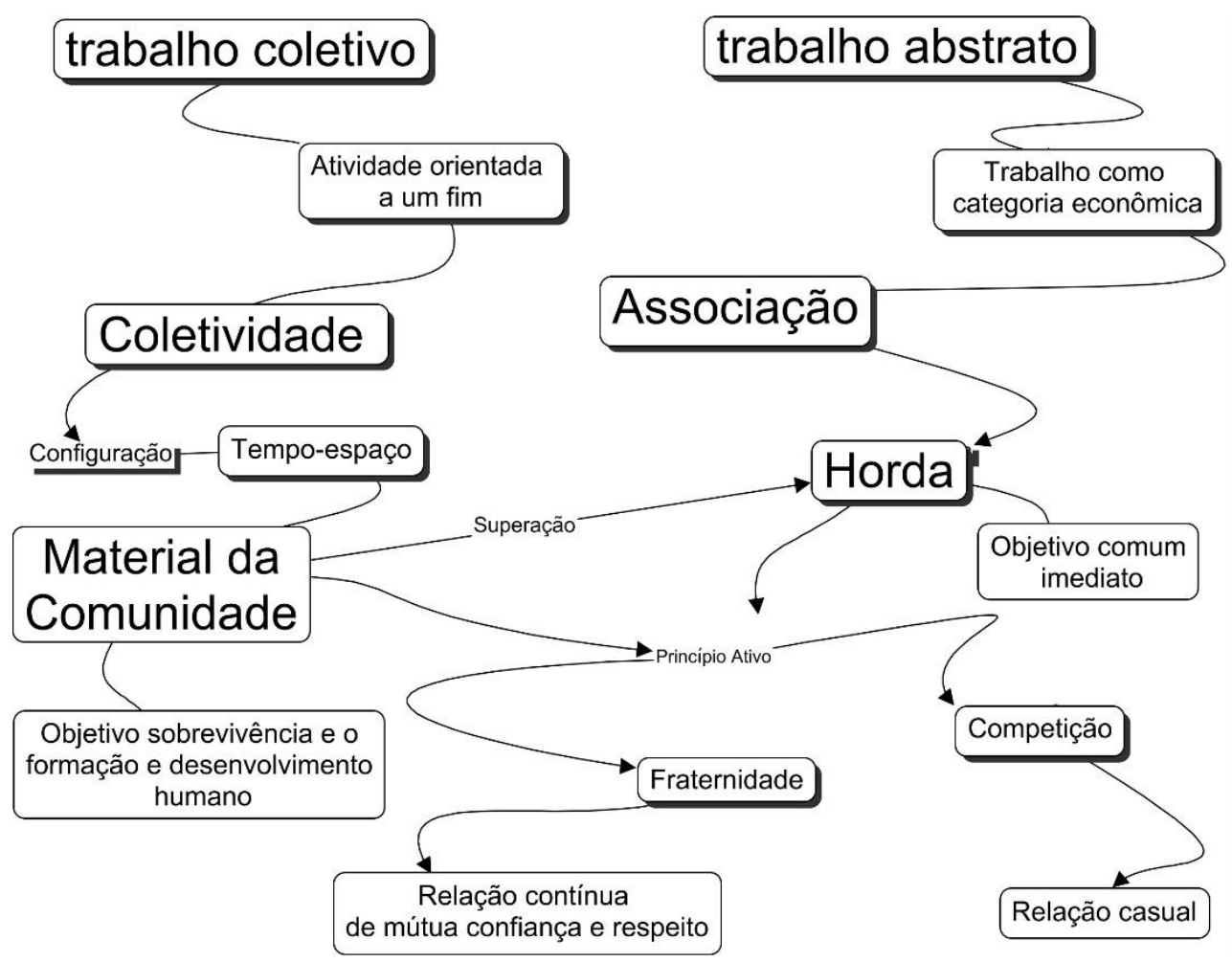

Fonte: Elaborado pelas autoras

Como esquematizado, associação não é sinônimo de fraternidade cuja configuração visa uma comunidade cujo trabalho coletivo visa o processo de humanização para transformação da sociedade e não a sua adaptação. Desse modo, a auto-organização dos seres humanos ao partir do trabalho abstrato diferencia desta quando parte do trabalho coletivo que visa uma coletividade que "é a configuração específica, temporal (histórica), espacial (geográfica) e material da comunidade" que tem como "finalidade única e permanente a sobrevivência e o desenvolvimento da humanidade. O seu princípio ativo é a fraternidade" (MOURA et. al, 2016, p. 252).

Portanto, somente o trabalho humano comprometido com a coletividade opera visando a comunidade, este processo não ocorrerá espontaneamente como será discutido nos próximos itens cujo objetivo é afirmar a importância da coletividade de professores como possibilidade de resistência ao trabalho abstrato. Para tanto, apresenta primeiramente a unidade entre a coletividade e a formação humana. 


\section{A unidade entre a coletividade e a formação humana}

A coletividade viabiliza o entendimento que o ser humano é "o representante do humano-genérico não é, jamais, um homem sozinho, mas sempre a integração (tribo, demos, estamento, classe, nação, humanidade) - bem como, frequentemente, várias integrações - cuja parte consciente é o homem, no qual se forma sua 'consciência de nós"' (HELLER, 2008, p. 21), como esquematizado na Figura 3.

Figura 3: A coletividade

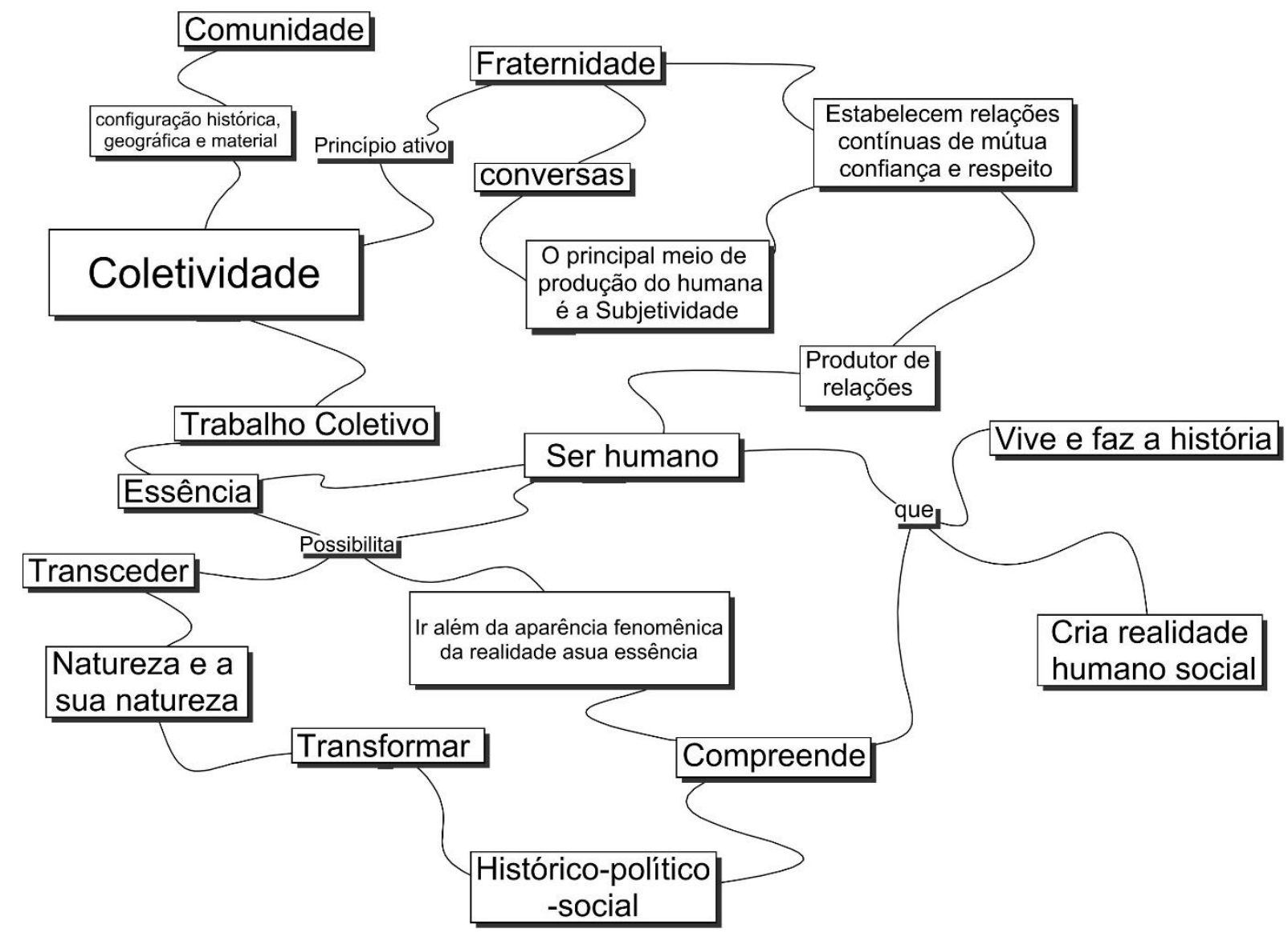

Fonte: Elaborada pela autora a partir de Kosik (1976), Pistrak (2011) e Heller (2008).

A coletividade preconiza a possibilidade concreta da transformação da sociedade, pois visa as condições essenciais para o homem criar e viver a história de maneira interligada, iniciada em sua luta para sobreviver e que, ao buscar as condições materiais, desencadeia a produção de novos meios e, consequentemente, a produção de novas necessidades, ambas relacionadas ao fato de se relacionarem com outros homens em diferentes ambientes sociais. 
Dessa forma, a coletividade indica a possibilidade dos seres humanos em desenvolver, enquanto, categoria filosófica, a possibilidade indissociável da realidade, pois "a realidade é o que existe realmente e a possibilidade é o que pode produzir-se quando as condições são propícias" (CHEPTULIN, 1982, p. 338).

Considerando que na realidade no sistema capitalista auto-organização das escolas toma como base $o$ trabalho abstrato, que tem como função educativa 0 ensino dos conceitos, da individualidade e da competição e estes conceitos a serem ensinados visam a manutenção do seu modo de produção, pois a individualidade é que permite responsabilizar o ser humano individualmente, por não conseguir apropriar-se da cultura e não desvela que a divisão social do sistema capitalista sempre sonegou a efetivação desse direito a todos de maneira igualitária.

Assim, o trabalho docente não foi poupado dos interesses em atender ao sistema, pois influencia as políticas sociais, inclusive a educacional e se espalha, mas, isto não indica a possibilidade de um trabalho coletivo nas escolas visando uma coletividade, mas sim, da sua importância para "formar os professores e estudantes com a intencionalidade de desenvolver significações e superação da alienação docente", que "apropriem e desenvolvam o pensamento teórico" (BRITO; ARAÚJO, 2019, p. 609). No próximo item partindo do conceito como atividade defende a coletividade de professores como uma possibilidade de resistência ao trabalho abstrato.

\section{Análise da coletividade de professores como possibilidade de resistência ao trabalho abstrato na docência}

Fundamentado na Perspectiva Histórico-Cultural, em consonância com MHD, os estudos apresentados neste artigo indicam uma unidade entre coletividade e a formação-desenvolvimento humano, que é individual-social e que apontou um caminho para a discussão da coletividade de professores como possibilidade de resistência ao trabalho abstrato. Sua pertinência situa-se na tentativa de contextualizar a coletividade a partir da compreensão do trabalho docente como uma atividade fonte de sua formação e desenvolvimento e o torna responsável pelo processo de humanização, mas é indissociável do individual-social.

Martins (2011), assevera a importância de que os professores estabeleçam uma "relação consciente" acerca da importância da medicação que ocorre no ato educativo, pois ele oportuniza o "desenvolvimento das atividades fundamentais e
Revista Labor, V. 1, N. 25 
Programa de Pós-graduação em Educação, Universidade Federal do Ceará

Fortaleza-CE-Brasil

objetivas de humanização" Ihes dará condições em seu trabalho de efetivar "educabilidade do ser humano". Ora, este trabalhador negará uma "formação exclusiva da mão de obra" (MARTINS, 2011, p. 149) para seus alunos que são exigidas pelo sistema capitalista.

$\mathrm{Na}$ Perspectiva Histórico-Cultural em consonância com $0 \mathrm{MHD}$, a possibilidade pode ser: abstrata ou concreta, assim, abstrata "é uma possibilidade para cuja realização não há, no momento presente, condições necessárias" já concreta "é a possibilidade para cuja realização podem ser reunidas, no momento presente, as condições correspondentes", mas o conhecimento das possibilidades vislumbra "interferir no curso objetivo dos acontecimentos, criando artificialmente as condições requeridas, acelerar ou refrear sua transformação em realidade" (CHEPTULIN, 1982, p. 342).

Segundo Cheptulin "com efeito, todas as operações do trabalho nada mais são do que ações que visam criar as condições necessárias para a realização dessas ou daquelas possibilidades conhecidas, próprias aos objetos" bem como, "aos fenômenos da natureza, introduzidas nos processos de produção" (CHEPTULIN, 1982, p. 342).

Desse modo, os estudos de Pistrak (2011) que também está no cerne da Perspectiva Histórico-Cultural, concebem a importância da escola na educação como formação humana em todas as dimensões, e ainda, teoriza, no tocante aos impactos quando segue-se nessa instituição social, a lógica do sistema capitalista cuja finalidade da educação é atender o seu modo de produção. Esta não será desvelada pelo professor caso este fique "isolado, abandonado a si mesmo", sendo, sim, fundamental "um trabalho coletivo, da análise coletiva do trabalho de uma escola, mas essa é uma qualidade a ser ensinada" (PISTRAK, 2011, p. 21).

Vivenciando um contexto histórico, o autor preconizou a luta pela formação de um novo homem - desencadeado pela revolução - portanto, a escola tinha a responsabilidade de ensinar o conceito de trabalho coletivo, isto é, como atividade orientada a um fim. Desse modo, propôs uma nova auto-organização para as instituições de ensino visando ensinar o referido conceito que tinha por objetivo ser um instrumento de luta contra o modo de produção capitalista, pois ao partir do conceito de trabalho coletivo oportuniza a compreensão de que uma sociedade envolve uma totalidade onde todos os seres humanos são importantes e, assim, a 
Programa de Pós-graduação em Educação, Universidade Federal do Ceará

Fortaleza-CE-Brasil

apropriação da cultura é condição na constituição dessa sociedade na unidade com um ser social.

Pistrak (2011), não corrobora com a pauta do modo de produção capitalista, cuja auto-organização das escolas toma como base o trabalho abstrato que tem como função educativa o ensino dos conceitos da individualidade e da competição e estes conceitos a serem ensinados visa a manutenção do seu modo de produção, pois a individualidade é que permite responsabilizar o ser humano individualmente, por não conseguirem apropriar-se da cultura e não desvela que a divisão social do sistema capitalista sempre sonegou a efetivação desse direito a todos de maneira igualitária.

Assim, para a educação como formação humana, visando contribuir com a nova sociedade que tem por objetivo o trabalho coletivo, o autor afirma que os conceitos de solidariedade e cooperação serão aproximados desta instituição social. Assim, partindo do conceito de trabalho coletivo, propôs uma nova auto-organização que preconiza "a iniciativa coletiva, a responsabilidade correspondente à sua atividade", portanto, o coletivo nestas instituições tornará realidade na própria autoorganização.

A coletividade é a possibilidade do ser humano tornar-se histórico, social e político, e a constituição de uma coletividade de professores propicia o nascimento de uma nova forma de pensar e ensinar partindo da afirmação de Moura et al que diz: "do real universal chama-se objetividade e o reconhecimento do outro semelhante chama-se fraternidade" e da unidade dialética entre objetividade-fraternidade tem-se uma comunidade (MOURA et al., 2016).

De fato, a coletividade visa o desenvolvimento do trabalho como atividade, que é um sistema dinâmico, que representa uma formação coletiva elaborada em um longo processo histórico-social, mediado por meio de instrumentos e signos comuns e concentrado em um objeto ou motivo comum. De acordo com Fichtner (2010), a atividade humana tem uma "qualidade social", pois com ela os seres humanos se orientam por objetivos, agindo de forma intencional, por meio de ações planejadas e, ainda, efetivam as suas relações sociais com a realidade, com os outros indivíduos e consigo mesmos. Assim, o seu desenvolvimento humano, indica a relação do desenvolvimento social e individual como processo dialético no qual o trabalho os diferenciou dos outros animais possibilitando-os criar a sua cultura a história e a mediação cultural, fato universal de nossa espécie. Dessa forma, a aprendizagem tem 


\section{Revista Labor}

Programa de Pós-graduação em Educação, Universidade Federal do Ceará Fortaleza-CE-Brasil

a função de apropriação, não de adaptação, consequentemente, o seu desenvolvimento é sempre algo novo possível de compreensão.

$\mathrm{Na}$ coletividade de professores, como esquematizado na Figura 4, para o professor "se tornar um conhecedor (produtor de relações, de conhecimentos) é necessário entabular conversas, que é o ponto de partida da própria humanização, pois na sua produção "ele se humaniza na medida que cede espaço ao reconhecimento simultâneo da totalidade e do outro", pois "a subjetividade é o principal produto da conversa" (MOURA et al., 2016, p. 128).

Figura 4: A coletividade de professores

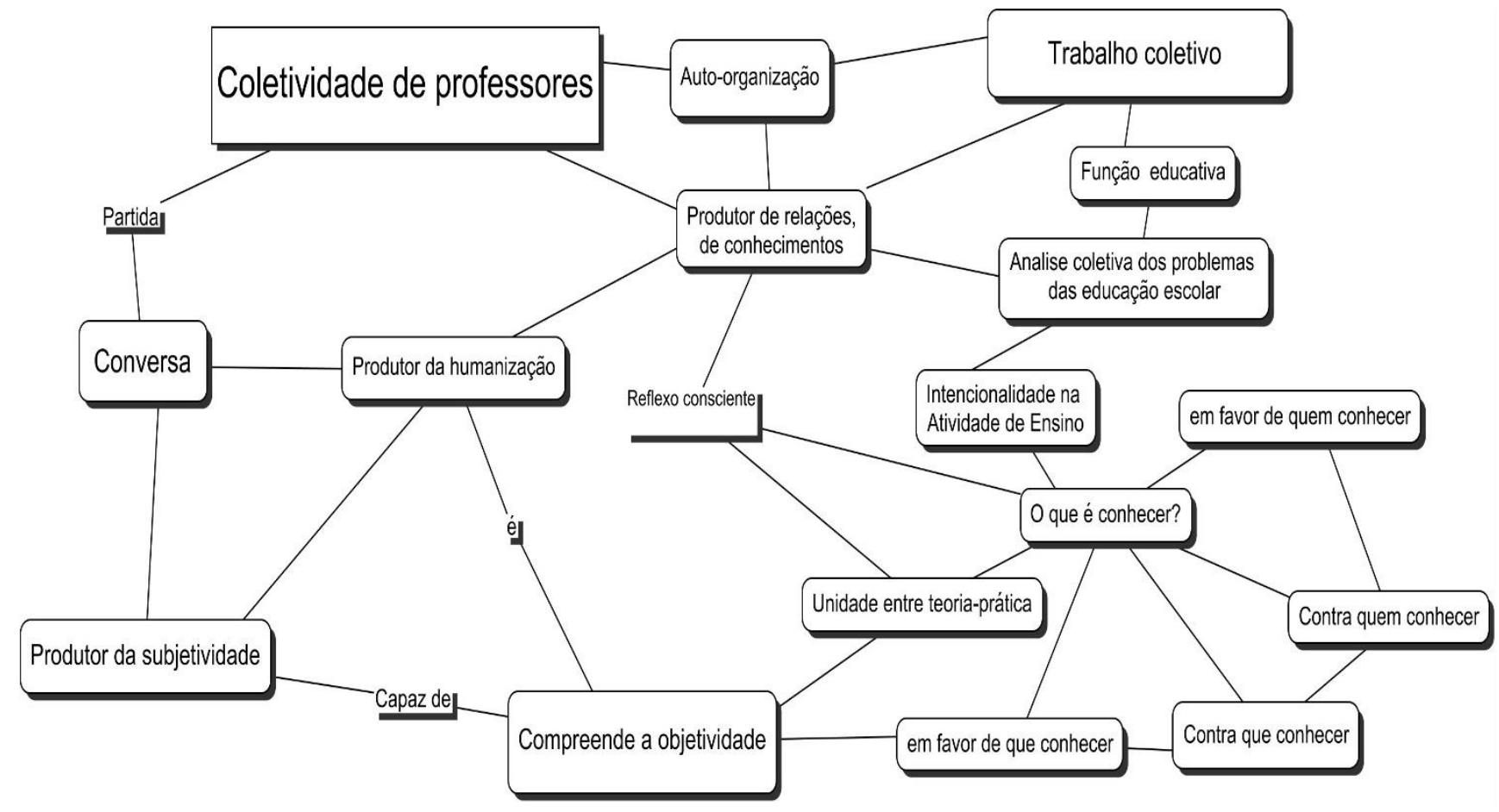

Fonte: Elaborada pelas autoras

Uma coletividade de professores oportuniza aos membros que ao ensinar o conteúdo, deve-se compreender o "que é conhecer e qual é esse conhecimento" visando que, a partir de uma dinâmica dialética, seja concebida a educação como "ato de conhecimento", consequentemente, um "ato político" levando a questionar "em favor de que conhecer e, portanto, contra que conhecer; em favor de quem conhecer e contra quem conhecer". Desse modo, desencadeia outras questões entre elas "em favor de que e contra que, em favor de quem e contra quem eu conheço, nós conhecemos" (FREIRE, 1986, p. 101). 
A conversa, sinônimo de diálogo, "é uma espécie de postura necessária, na medida em que os seres humanos se transformam cada vez mais em seres criticamente comunicativos", pois o diálogo "é o momento em que os humanos se encontram para refletir sobre sua realidade, tal como a fazem e re-fazem" (FREIRE, 1986 , p. 101) e, "na medida em que somos seres comunicativos, que nos comunicamos uns com os outros enquanto nos tornamos mais capazes de transformar nossa realidade, somos capazes de saber que sabemos" (FREIRE, 1986, p. 65).

Partindo desses princípios, ao visar a constituição de uma coletividade, os professores devem, também, compreender que, as lutas da comunidade educacional organizada favoreceram a conquistas expressas no Art. 206 da Constituição Federal.

Art. 206. O ensino será ministrado com base nos seguintes princípios: I igualdade de condições para o acesso e permanência na escola; II liberdade de aprender, ensinar, pesquisar e divulgar o pensamento, a arte e o saber; III - pluralismo de ideias e de concepções pedagógicas e coexistência de instituições públicas e privadas de ensino; IV - gratuidade do ensino público em estabelecimentos oficiais; $\mathrm{V}$ - valorização dos profissionais do ensino, garantido, na forma da lei, plano de carreira para o magistério público, com piso salarial profissional e ingresso exclusivamente por concurso público de provas e títulos, assegurado regime jurídico único para todas as instituições mantidas pela União; VI - gestão democrática do ensino público, na forma da lei; VII - garantia de padrão de qualidade (BRASIL, 1988).

No entanto, Freitas (2018c), alerta que as referidas conquistas que não foram dadas pelos governantes, mas, sim, foram fruto de muita luta da comunidade organizada, mas "vêm sendo violados, em maior ou menor grau de extensão, no conjunto das políticas desenvolvidas ao longo destes 30 anos" (FREITAS, 2018c, p. 513).

De fato, a partir da década de 1970, apesar do acordo firmado pelas grandes potências econômicas do sistema capitalista, que iniciou após a Segunda Guerra Mundial, que afirmava a necessidade do Estado garantir direitos sociais ao ser humano, esse acordo se rompeu, isto é, tornou-se o Estado mínimo devido ao surgimento do neoliberalismo. Assim, esta nova ordem econômica visa a manutenção do sistema e o Estado é considerado como uma instituição cujo funcionamento visa atender aos interesses das políticas econômicas, assim, a eficiência, a qualidade e a equidade desta instituição social esta relacionada aos interesses do mercado e o modelo privado deve ser seguido para não prejudicar o sistema econômico. 
Aqui vale a observação do Freitas (2018a) que afirma que o sistema capitalista para "atender às necessidades do novo padrão de exploração da classe trabalhadora" traz implicações para a docência, pois expropria o professor do seu "trabalho vivo do magistério" e o transpõe como "trabalho morto" no interior de manuais impressos e/ou propõe "plataformas de aprendizagem online" e "personalizada, com tecnologia adaptativas e "avaliação embarcada" (Freitas, 2018a, p. 105).

Antunes (2018) corrobora com o autor quando afirma que as transformações no modo de produção capitalista levaram a uma nova fase da automação industrial denominada indústria 4.0, sua lógica é "destrutiva em relação ao mundo do trabalho", pois bilhões de trabalhadores, em pleno século XXI, são inseridos em situações de "mais precarização, mais informalidade, mais subemprego, mais desemprego, mais trabalhadores intermitentes, mais eliminação dos postos de trabalho, menos pessoas trabalhando com os direitos preservados" (ANTUNES, 2018, p. 38).

Como evidenciado por Freitas (2018b), vive-se no Brasil atual a destruição das relações de trabalho com a política ultraliberal do governo Bolsonaro, que tem dado continuidade à finalidade da educação preconizada pelas políticas neoliberais e, ainda, o autor considera que a compreensão da realidade é imprescindível no estabelecimento de caminhos para a luta, pois os que vivem nela sabem que há momentos de avançar e os de resistir sendo que este não é sinônimo de imobilismo e, sim, um caminho para avançar.

Freire (2014) corrobora com a concepção do autor no tocante a resistência quando afirma que é "preciso, porém que tenhamos na resistência que nos preserva vivos, na compreensão do futuro como problema e na vocação para o ser mais", isto é, "como expressão da natureza humana em processo de estar sendo, fundamentos para a nossa rebeldia e não para a nossa resignação em face das ofensas que nos destroem o ser" (FREIRE, 2014, p. 76).

Mediante o exposto, a coletividade dos professores, inter-relaciona-se com a possibilidade de resistência ao trabalho abstrato na docência, isto é, como um caminho para avançar contra a organização social do trabalho no modo de produção capitalista. De fato, a coletividade vislumbra uma solidariedade entre os membros e o compromisso com 0 trabalho sendo este trabalho fonte da formação $e$ 
Revista Labor

Programa de Pós-graduação em Educação, Universidade Federal do Ceará

Fortaleza-CE-Brasil

desenvolvimento humano e defende o desenvolvimento da docência como trabalho, isto é, uma atividade.

\section{Considerações finais}

O presente artigo buscou analisar e discutir o conceito de coletividade para afirmar a relevância da resistência ao trabalho abstrato na docência fundamentado na Perspectiva Histórico-Cultural. Para tanto, estudou o conceito de trabalho como atividade orientada a um fim que se distingue do trabalho abstrato cuja origem visa atender o modo de produção capitalista.

Desse modo, esta investigação teórico-bibliográfica oportunizou a compreensão que o modo de produção da vida material condiciona o processo de vida social, política e intelectual, indicando que o homem é o concreto em uma sociedade, pois as diferentes instituições são criadas por ele, inclusive o Estado, que é abstrato, reduz o trabalho humano, que é sua atividade orientada a um fim, a fonte de formação e desenvolvimento humano diferente do trabalho abstrato cuja origem visa atender à organização social do trabalho do sistema capitalista e não preconiza uma coletividade dos seres humanos, e sim, associação.

A pesquisa demonstrou ao articular as categorias possibilidade-realidade que a organização social do trabalho no modo de produção capitalista não poupou os professores que são responsáveis pelo processo de humanização, mas é indissociável do indivíduo-sociedade. De fato, concordando com Martins (2011) o "trabalhador professor objetiva-se no produto de seu trabalho, tendo neste produto a promoção intencional da humanização do outro e de sua própria humanidade" (MARTINS, 2011).

Partindo disso, quando o significado do trabalho do professor se distancia do seu sentido acaba resumindo a docência a trabalho abstrato prejudica sua formação e desenvolvimento e de toda sociedade. A realidade evidencia que os professores vivenciam os resultados das mudanças políticas ocorridas no Brasil, em 2016, que favoreceu a agenda neoliberal da educação, que visa atender ao sistema capitalista, portanto, um retrocesso para o trabalho docente.

No entanto, como realidade-possibilidade são indissociáveis, aproximar os professores de uma auto-organização que visa uma coletividade Ihes possibilitam vivenciar a importância do trabalho como atividade orientada a um fim, fonte de 
Programa de Pós-graduação em Educação, Universidade Federal do Ceará

Fortaleza-CE-Brasil

formação dos mesmos e desenvolvimento, que corrobora para a transformação da sociedade e não atende aos interesses do modo de produção capitalista.

Assim, a coletividade de professores favorece aos membros a compreensão da realidade que é imprescindível no estabelecimento de caminhos para a luta, pois os que vivem nela sabem que há momentos de avançar e momentos de resistir, sendo que este não é sinônimo de imobilismo e, sim, um caminho para avançar.

\section{Referências Bibliográficas}

ANTUNES, R. O privilégio da servidão: o novo proletariado de serviços na era digital. São Paulo: Boitempo, 2018.

BRASIL. Senado Federal. Constituição: República Federativa do Brasil. Brasília: Centro Gráfico, 1988. Disponível em: http://portal.mec.gov.br/index.php?option=com_content\&view=article\&id=12907:legis| acoes\&catid=70:legislacoes. Acesso em: 5 jun. 2017.

CHARLOT, B. Da relação com o saber: elementos para uma teoria. Trad. Bruno Magne. Porto Alegre: Artes Médicas Sul, 2013.

CHEPTULIN, A. A dialética materialista: categorias e leis da dialética. Trad. de Leda Rita Cintra Ferraz. São Paulo: Editora Alfa-Omega, 1982.

FICHTNER, B. O. Introdução na abordagem histórico-cultural de Vygotsky e seus Colaboradores. $2010 . \quad$ Disponível em: http://www3.fe.usp.br/secoes/inst/novo/agenda_eventos/docente/PDF_SWF/226Rea der\%20Vygotskij.pdf. Acesso em: 16 maio $201 \overline{8}$.

FREIRE. P. Pedagogia do oprimido. 41ํㅡㄹ ed. Rio de Janeiro: Paz e Terra, 2014.

FREIRE. P. O que é "método dialógico" de ensino? o que é uma "pedagogia situada" e empowerment? In: FREIRE, P.; SHOR, I. Medo e ousadia. O cotidiano do professor. Rio de Janeiro: Paz e Terra, 1986.

FREITAS, C. L. A reforma empresarial da educação: nova direita, velhas ideias. 1. ed. São Paulo: Editora Expressão Popular, 2018a.

FREITAS, C. L. Escolas aprisionadas em uma democracia aprisionada: anotações para uma resistência propositiva. Revista HISTEDBR On-line, v. 18, p. 906-926, 2018b. Disponível em: file://C:/Users/susiv/Downloads/8654333-46764-2-PB.pdf. Acesso em: 9 de jan. 2019.

FREITAS, H. C. L. 30 Anos da Constituição Avanços e retrocessos na formação de professores. Revista Retratos da Escola, Brasília, v. 12, n. 24, p. 511-527, nov./dez. 
Programa de Pós-graduação em Educação, Universidade Federal do Ceará

Fortaleza-CE-Brasil

2018. Disponível em: http://retratosdaescola.emnuvens.com.br/rde/article/view/912.

Acesso em: 12 abr. 2019.

FRIGOTTO, G. O enfoque da dialética materialista histórica na pesquisa educacional. In: FAZENDA, I. (Org.). Metodologia da pesquisa educacional. 12 ${ }^{a}$ ed. São Paulo: Cortez, 2010b.

HELLER, A. O Cotidiano e a História. 8ª ed. São Paulo: Paz e Terra, 2008.

KOPNIN, P. V. A dialética como lógica e teoria do conhecimento. Rio de Janeiro: Civilização Brasileira,1978.

KOSIK. K. A Dialética do Concreto. $2^{\underline{a}}$ ed. Tradução de Célia Neves e Alderico Toríbio. Rio de Janeiro: Paz e Terra, 1976.

LEONTIEV, A. N. Desenvolvimento do psiquismo. Lisboa: Livros Horizonte, 1978.

LOMBARDI, J. C. Educação e Ensino na obra de Marx e Engels. Campinas, SP: Editora Alínea, 2011.

MARTINS, L. M. A Formação Social da Personalidade do Professor: Um Enfoque Vigotskiano. Campinas: Autores Associados, 2011.

MARX, K. O capital. Crítica da economia política: livro I. O processo de produção do capital. Trad. Rubens Enderle. 2ª ed. São Paulo: Boitempo, 2017.

MOURA, A. R. L.; LIMA, L.C.; MOURA, M. O.; MOISÉS, R.P. Educar com a Matemática - Fundamentos. São Paulo: Cortez, 2016.

PISTRAK, M.M. Fundamentos da Escola do Trabalho. 3ํㅡ. São Paulo: Expressão Popular, 2011.

\section{Susimeire Vivien Rosotti de Andrade}

Foz do Iguaçu, Paraná, Brasil.

Licenciada em Matemática pela Universidade Estadual do Oeste do Paraná (UNIOESTE), Mestre em Educação para a Ciência e a Matemática pela Universidade Estadual de Maringá (UEM) e Doutora em Educação Matemática pela Universidade Federal do Mato Grosso do Sul - UFMS, Atualmente é docente do curso de Licenciatura em Matemática e do Programa de Pós-Graduação em Ensino (PPGEn) da UNIOESTE. Líder do Grupo de Estudos e Pesquisas em Educação Matemática e Trabalho Docente (GEPEMTD).

E-mail: susimeire.andrade@unioeste.br

Link do Lattes: http://lattes.cnpq.br/7645006700133174 


\section{Patricia Sandalo Pereira}

Campo Grande, Mato Grosso do Sul, Brasil.

Graduada em Ciências Habilitação Plena Em Matemática pela Universidade Federal de Uberlândia, mestre em Educação Matemática e doutora em Educação Matemática pela Universidade Estadual Paulista Júlio de Mesquita Filho (UNESP). Atualmente é docente do curso de Licenciatura em Matemática e do Programa de Pós-Graduação em Educação Matemática e Docente do Doutorado em Ensino de Ciências da Universidade Federal de Mato Grosso do Sul (UFMS). Líder do Grupo de Pesquisa FORMEM - Formação e Educação Matemática.

E-mail: sandalo.patricia13@gmail.com

Link do Lattes: http://lattes.cnpq.br/9126213537245312

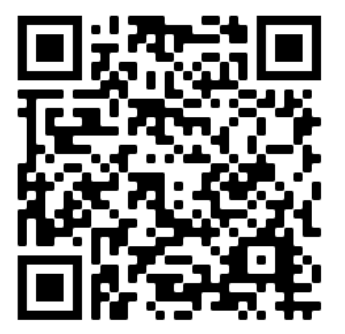

\section{Q. Code}

\section{Editores-Responsáveis}

Dr. Enéas de Araújo Arrais Neto, Universidade Federal do Ceará, UFC, Ceará, Brasil

Dr. Sebastien Pesce, Universidade de Orléans, França 